\title{
Mouse models for telomere and telomerase biology
}

\author{
Cheolho Cheong ${ }^{1}$, Kyung Uk Hong ${ }^{1}$ \\ and Han-Woong Lee ${ }^{1,2}$
}

\author{
${ }^{1}$ Samsung Biomedical Research Institute \\ Department of Molecular Cell Biology \\ Sungkyunkwan University School of Medicine \\ Suwon 440-746, Korea \\ ${ }^{2}$ Corresponding author: Tel, 82-31-299-6135; \\ Fax, 82-31-299-6435; E-mail, hwl@skku.ac.kr
}

Accepted 31 May 2003

Abbreviations: SKY, spectral kargotyping; TERC, template RNA component, TERT, telomerase reverse transcriptase

\begin{abstract}
Telomeres serve a critical role in maintenance of genomic stability in all eukaryotes, from yeast to human. The maintenance of telomeres is achieved by the telomerase complex, which is largely composed of telomerase reverse transcriptase (TERT) and telomerase RNA component (TERC). A variety of mouse models have provided valuable insights into the relationship between the telomerase complex and telomere dysfunction at the organismal level and helped understand their biological significance in human. Recently, in addition to its role in maintenance of the telomeres, novel functions of the telomerase complex have been emerging. In this review, studies of all gene-targeted or transgenic mouse models so far generated for telomerase and telomere biology are comprehensively described, and potential novel functions of telomerase are briefly discussed.
\end{abstract}

Keywords: mouse model; telomerase; telomere; transgenic mouse

\section{Telomere and Telomerase}

Telomeres are specialized structures that cap the ends of eukaryotic chromosomes and consist of tandem repeats of the TTAGGG sequence that are associated with an array of proteins (Blackburn, 1991). The telomere serves critical biological functions. The telomere is believed to be important in maintaining the genomic stability of the cells, as well as in allowing complete replication of chromosomes (Greider, 1991). With each cell division, the telomere shortens progressively as a consequence of the end replication problem, which is caused by the inability of the conventional DNA polymerase to fully replicate the $3^{\prime}$ end of the lagging strands of the linear DNA molecules. It has been hypothesized that this shortening of the telomere functions as molecular clock in monitoring the replicative history of cells (Wright and Shay, 2002). Maintenance of telomeres ultimately provides a foundation for a stable structure of T-loop and D-loop and makes the capping function possible (Griffith et al., 1999). Lack of telomere maintenance results in improper telomere capping which, in turn, can lead to telomere dysfunction. For instance, the loss of the protective telomeric capping function leads to active degradation of the telomeric G-strand overhangs, and uncapped telomeres are known to be highly recombinogenic (Summarized in Figure 1).

Telomerase is a ribonucleoprotein and consists of two essential components: a template RNA component (TERC) containing the complementary sequence of TTAGGG and a catalytic component (TERT) with reverse transcriptase activity. It is involved in the synthesis of the telomeric sequences, thus compensating for their progressive shortening with each round of DNA replication (Meyerson et al., 1997). In addition to TERT and TERC which are essential for the catalytic activity of the telomerase, telomerase complex is also composed of chaperones, including hsp90 and p23, and proteins that bind to TERC, including TEP1, dyskerin, hStau, and L22. (Summarized in Table 1). However, it is still unclear how these different factors might interact with one another in formation of the telomerase holoenzyme complex, and further studies are needed.

Telomere biology which evolved around yeast and Tetrahymena has now prospered with actively ongoing aging and cancer research with the recent emergence of various mouse models of the telomerase complex and telomere-binding proteins. Functional studies on telomere and telomerase through these mouse models can provide valuable information that is directly applicable to human aging and cancer research field. This review will provide a summary of previously reported mouse models for the studies of telomere and telomerase biology and discuss future directions. 


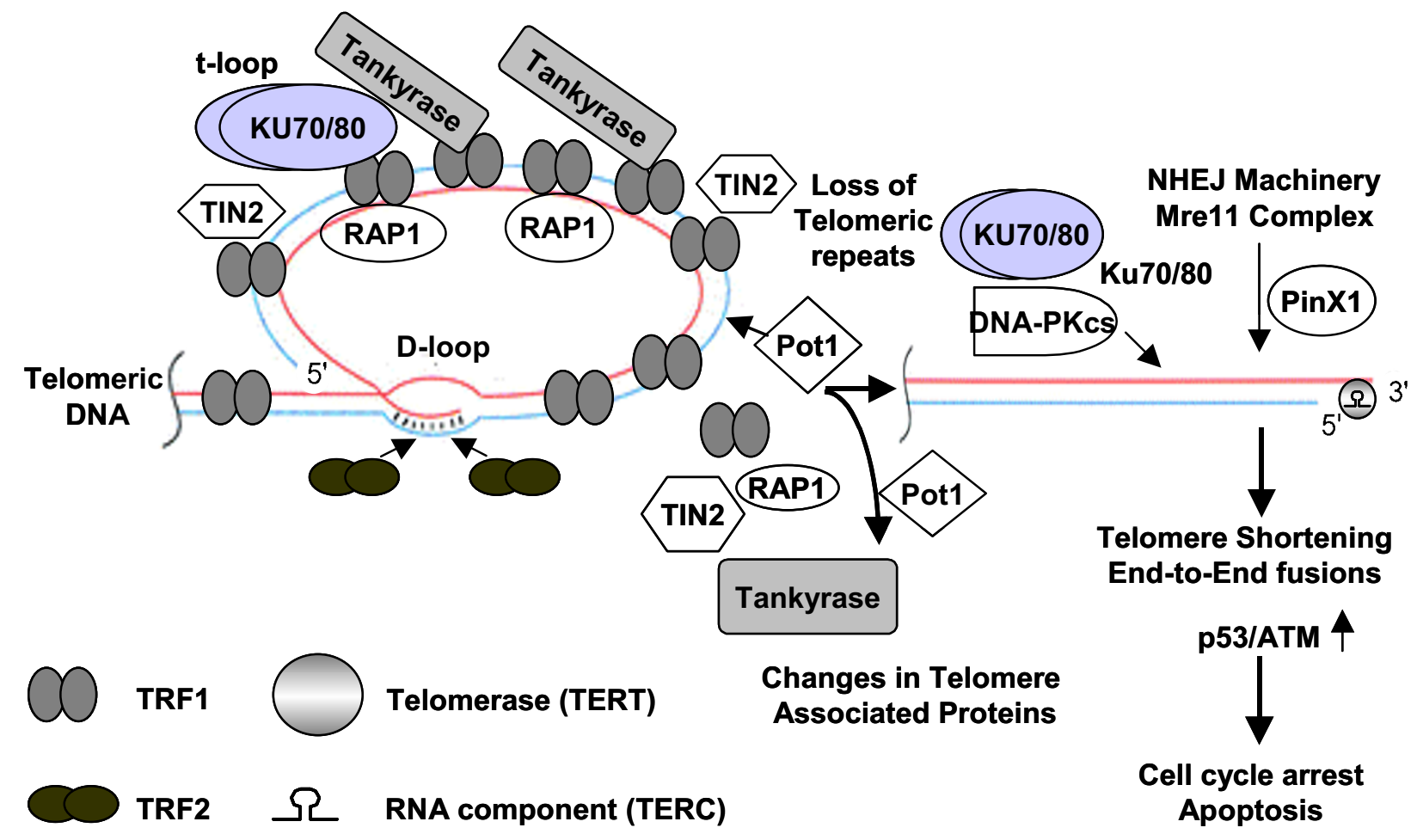

Figure 1. Structure of telomere and associated proteins.

\section{Telomere Hypothesis (M1 and M2 hypothesis)}

Telomere hypothesis states that cellular senescence is triggered by the shortening of telomere repeats to a critical length due to the loss of telomerase function while cellular immortalization is accompanied by telomerase reactivation. In normal fibroblasts, the progressive shortening of telomeres to a critical length is associated with activation of a growth-arrested senescent state known as mortality stage 1 (M1). The molecular basis of $\mathrm{M} 1$ is poorly understood, but a number of studies have suggested that $R b, p 53$, and p21 are involved in the process (Harley and Villeponteau, 1995). Two models have been proposed for the induction of M1. One model postulates that the loss of telomeric repeats exposes chromosomal ends that are then recognized by the DNA repair machinery that signals an anti-proliferative mechanism that involves $\mathrm{Rb}$ and $\mathrm{p} 53$ pathways. The other model, although not mutually exclusive with the first one, states that growth-suppressor genes involved in the induction of $\mathrm{M} 1$ are buried, and hence silenced, in the heterochromatic telomeric regions of chromosomes. Progressive shortening of the telomeres would lead to a chain of events involving relaxation of the chromatin structure of the subtelomeric heterochromatic region, derepression of senescence genes in- volved in the negative control of cell cycles, and subsequent proliferative arrest. During the M2 stage, most of human fibroblast cells die from a continuous shortening of telomeres, but a rare population of cells survive by regaining the telomerase activity and thus maintaining the telomere length (Shay and Wright, 2000). These cells are known to be immortalized, and tumor cells are considered to be at this stage.

In support of the telomere hypothesis, studies on telomerase expression have consistently demonstrated the presence of telomerase activity in the majority of various cancerous tissues, as well as in immortalized cells, and the absence of detectable level of telomerase activity in most normal somatic tissues (Kim et al., 1994). The telomerase activity present in most neoplastic lesions appears to be necessary for the sustained proliferation of most advanced cancers. In contrast, most somatic mammalian tissues and primary cells possess low or undetectable telomerase activity, and the telomeres shorten with each cell division in vivo and in vitro (Harley et al., 1995). After a certain number of cell divisions, known as the Hayflick limit, a critical telomere length is eventually reached, leading to cellular senescence, and this provides a basis for the limited replicative capacity of cultured cells (Hayflick and Moorhead, 1961; Shay and Wright, 2000). Telomere shortening appears to trigger senescence via $\mathrm{Rb}$ and $\mathrm{p} 53$ pathways, since 
Table 1. Summary of telomere and telomerase complex binding proteins.

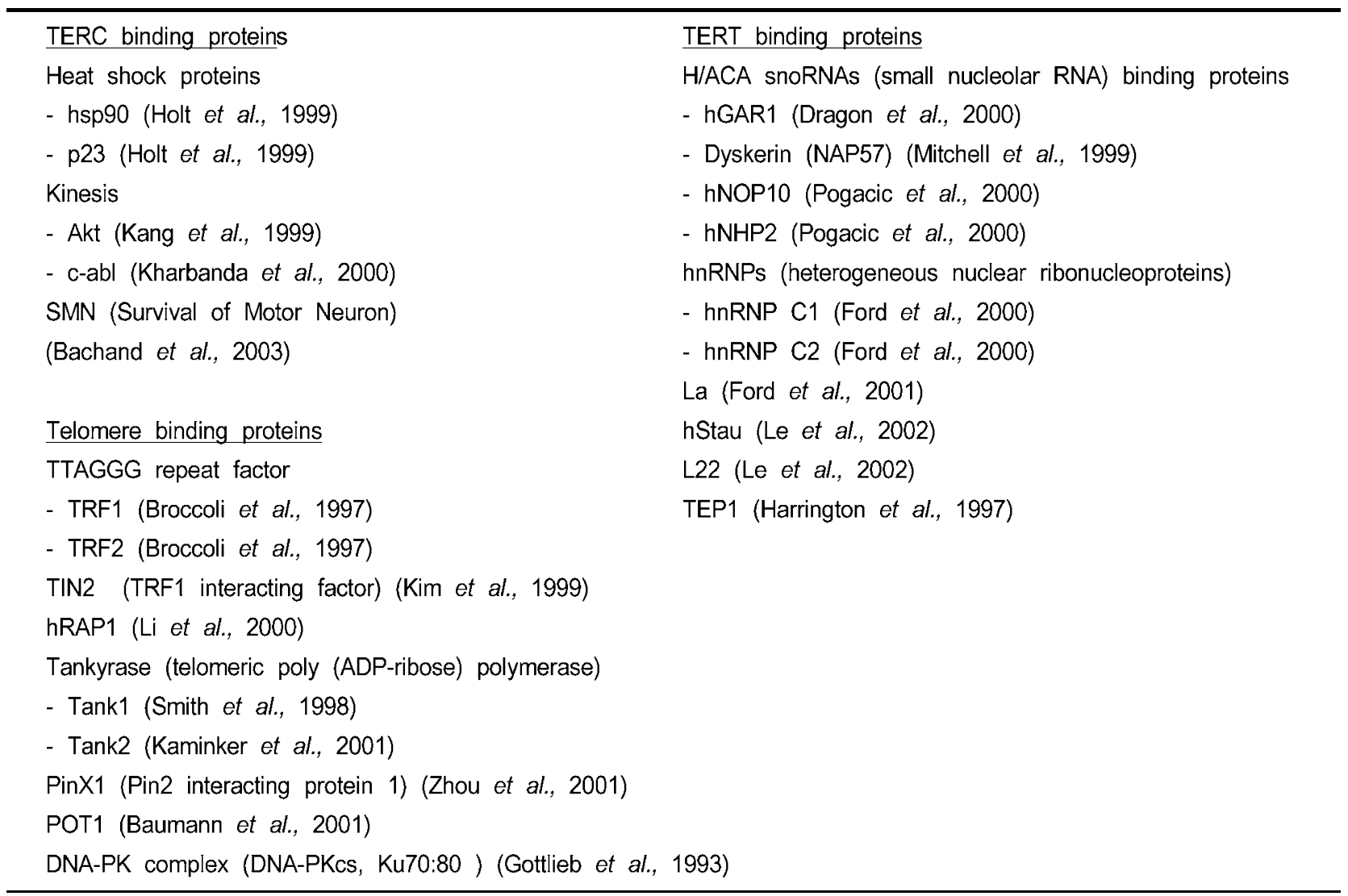

cell divisions beyond the Hayflick limit can occur after antisense neutralization or inactivation of $\mathrm{Rb}$ and $\mathrm{p} 53$ by viral oncoproteins (Shay et al., 1991). In primary cells deficient for $\mathrm{Rb}$ and $\mathrm{p} 53$, continued cellular growth beyond the Hayflick limit results in severe telomere shortening, marked genomic instability, and massive cell death - a period referred to as crisis (Harley et al., 1995). While most cells transiting through crisis die, a rare population of surviving cells surfaces which can now maintain the telomere length either by reactivation of telomerase or by utilization of an alternative pathway, a recombination-based mechanism (Yeager et al., 1999).

\section{Testing the Telomere Hypothesis in Mice}

Many questions surrounding the telomere hypothesis still had not been answered until 1996. The most direct method to address these questions in mammals was to develop knockout mouse models of the telomerase complex. At that time, TERT, the catalytic subunit of telomerase complex had not been cloned in mouse. However TERC, the RNA component of telomerase was available (Blasco et al., 1995). Therefore, mice deficient for TERC were generated by the gene targeting approach in order to examine the consequences of the absence of telomerase activity and subsequent telomere dysfunction.

\section{mTERC-deficient mouse}

Requirement for telomerase activity in tumor formation and cell viability had been tested by deleting the mouse telomerase RNA component (mTerc) from the mouse germline (Blasco et al., 1997; Lee et al., 1998). Of note, laboratory mice (Mus musculus) possess significantly longer telomeres on average compared to human. mTERC ${ }^{-/-}$mice lacked detectable telomerase activity and were viable for six generations. Telomeres were shown to shorten at a rate of $4.8 \pm 2.4 \mathrm{~kb}$ per generation in the $\mathrm{mTERC}^{-1-}$ background. Cells from the fourth mTERC $^{-/}$generation and onward possessed chromosome ends lacking detectable telomere repeats, and exhibited aneuploidy and chromosomal abnormalities, including end-to-end fusions. However, surprisingly, telomerase-deficient cells could be immortalized in culture, transformed by viral oncogenes, and generated tumors in nude mice 
following transformation. These results clearly show that telomerase is essential for telomere length maintenance but is not required for establishment of cell lines, oncogenic transformation, or tumor formation in nude mice (Blasco et al., 1997).

However, late-generation $\mathrm{mTERC}^{-/}$mice exhibited defective spermatogenesis, with increased programmed cell death (apoptosis) and decreased proliferation in the testis (Lee et al., 1998). The proliferative capacity of hematopoietic cells in the bone marrow and spleen was also compromised. These progressively adverse effects coincided with substantial erosion of telomeres and an increase in the frequency of both fusion and loss of chromosomes. Furthermore, aging $\mathrm{mTERC}^{-/}$mice showed signs of premature aging in highly proliferative organs and they exhibited a decreased stress response, such as decreased wound healing capacity (Rudolph et al., 1999). The role of telomerase in organ regeneration is further supported by the fact that mTERC $^{-1-}$ mice exhibit defects in liver regeneration and accelerated development of liver cirrhosis in response to chronic liver injury (Rudolph et al., 2000). These findings indicate an essential role for telomerase, and hence telomeres, in the maintenance of genomic integrity and in the long-term viability of organ systems with a high renewal rate.

$\mathrm{mTERC}^{-/-}$mice can be propagated for only a limited number of generations (Lee et al., 1998). In particular, $\mathrm{mTERC}^{-/}$mice with mixed genetic background were infertile at the sixth generation and showed serious hematopoietic defects. In addition, Herrera et al. (1999) found that a subset of mTERC ${ }^{-/-}$embryos did not develop normally and failed to close the neural tube, preferentially at the forebrain and midbrain. The severity of this defect increased with each generation, with $30 \%$ of the mTERC ${ }^{-1}$ embryos from the fifth generation showing the phenotype. Moreover, mTERC ${ }^{-1}$ kindred in a pure C57BL/6 background with shorter telomeres were only viable up to the fourth generation and also showed defects in closing of the neural tube. These findings suggest that this particular developmental process is among the most sensitive to telomere loss and chromosomal instability (Herrera et al., 1999).

A recent technical advance such as spectral karyotyping (SKY) made it possible to monitor individual chromosomal abnormality in mTerc deficient cells. Importantly, Hemann et al. (2001) found that the loss of telomere function and subsequent chromosomal fusions occurred preferentially on chromosomes with critically short telomeres by SKY analysis. According to this result, a critically short telomere, rather than average telomere shortening, is responsible for the initiation of telomere dysfunction and thus the phenotypes of mTERC ${ }^{-1-}$ mice. Possibly, critically short telomeres have fallen below the threshold of telomere re- peats required for efficient binding of telomere-associated proteins, such as TRF2 (Broccoli et al., 1997), or the formation of telomere loop structures for telomere capping (Griffith et al., 1999).

\section{mTERT-deficient mouse}

A couple of groups have produced mTERT knockout mice (Yuan et al., 1999; Liu et al., 2000a). These mice which showed no telomerase activity lacked any serious abnormalities under standard conditions, suggesting that TERT is primarily responsible for the catalytic activity of telomerase, and is not required for other vital functions (Yuan et al., 1999; Liu et al., 2000a). Telomere shortening was only observed in late generations of mTERT-deficient mice and the G-tails essential for the higher-order telomere were also intact. Although these investigators did not find reproducible differences in telomerase activity between wild-type and heterozygous embryonic stem (ES) cells or tissue, ES cells deficient in one allele of mTert lost telomeric DNA in successive passages (Liu et al., 2000a). These results contrast with $\mathrm{mTERC}^{+-} \mathrm{ES}$ cells, in which the average telomeric restriction fragment (TRF) length was virtually unchanged following prolonged culture (Niida et al., 1998). This indicates that TERT is the limiting component for telomere- length maintenance. However, the haploinsufficiency phenotype of mTert-deficient ES cells should be examined in various murine genetic backgrounds to explain the discrepancy between mTERC ${ }^{+/-}$and TTERT $^{+/-}$ES cells. Importantly, $\mathrm{mTERC}^{+/}$intercross with a mouse strain with shorter telomere such as Mus spretus showed haploinsufficiency, resulting in defects in telomere elongation (Hathcock et al., 2002). These results suggest that the RNA component may be also limiting under certain in vivo conditions.

\section{Role of Telomerase Complex- Associated Proteins in vivo}

Recent discovery of proteins that bind to the telomerase complex has led to generation of knockout mouse models for these proteins in attempt to assess the effects of their deficiency on telomerase and telomere maintenance.

\section{mTEP1-deficient mouse}

Mouse TEP1 (mTEP1) is a homologue of Tetrahymena telomerase protein $\mathrm{p} 80$ and was the first protein identified to be associated with the mammalian telomerase (Harrington et al., 1997). TEP1 was found to be associated with telomerase activity in immortalized-cell extracts from human, mouse and rat (Harrington et al., 1997; Nakayama et al., 1997). The 
amino-terminal 900 amino acids of TEP1 have been also shown to interact with telomerase RNA in vitro and in vivo by an RNA/protein interaction assay (Harrington et al., 1997). Despite its association with telomerase components, mTep1-deficient mice showed no significant change in telomerase activity and telomere length up to seven successive generations (Liu et al., 2000b). One possibility is that mTEP1 may share a redundant role with other telomerase RNAbinding proteins, such as L22, hStau, and dyskerin, with respect to the telomerase function (Mitchell et al., 1999; Le et al., 2000). Another possibility is that only a fraction of the total telomerase complex is associated with TEP1. Along these lines, not all telomerase-associated proteins appear to be restricted to the telomerase complex. Ubiquitous proteins, such as p23 and hsp90, are also associated with at least some fraction of the telomerase complex (Holt et al., 1999; Liu et al., 2000b). Furthermore, TEP1 expression is not restricted to the tissues with telomerase activity, suggesting that TEP1 may serve other cellular functions (Liu et al., 2000b; Kickhoefer et al., 2001).

\section{Dyskerin hypomorphic mutant mouse}

Dyskeratosis congenita (DC) is a rare $X$-linked recessive disease with features of premature aging, as well as nail dystrophy, mucosal leukoplakia, interstitial fibrosis of the lung, and increased susceptibility to cancer (Heiss et al., 1998; Dokal et al., 2000; Knight et al., 2001). DC is caused by mutations in DKC1, a gene coding for dyskerin. Dyskerin is known to be involved in rRNA processing and bind to the RNA component of mammalian telomerase (hTERC and mTerc) via H/ACA motif. Mutations in RNA component of telomerase also have been reported in DC (Vulliamy et al., 2001b). Interestingly, cell lines or tissues derived from DC patients display reduced telomerase activity and relatively shorter telomeres (Mitchell et al., 1999; Vulliamy et al., 2001a). Recently, Ruggero et al. (2003) produced a mouse model of DC that had reduced expression of DKC1. These hypomorphic mice reproduced the human DC phenotype within the first two generations. Although reduced mTerc expression and reduced telomerase activity was present within the first two generations, telomere shortening was only observed after four to six generations, closely resembling the phenotype of mTerc knockout mice (Ruggero et al., 2003). These data imply that DC might be caused by defects in both telomere maintenance and RNA processing.

\section{PinX1}

Pin2 is the 20 amino acid-deleted isoform of TRF1 and is more abundant than TRF1 in cells (Shen et al., 1997). Pin2/TRF1 is an important ATM kinase substrate involved in mitotic regulation and telomere maintenance (Kishi et al., 2001). Zhou et al. (2001) found 6 known genes and 4 unknown genes as Pin2/TRF1 interacting proteins by a yeast two-hybrid system. PinX1, one of the 4 unknown genes was a nuclear protein with 328 amino acid residues. When overexpressed in cells, PinX1 containing C-terminal 74 amino acids induced cellular crisis and reduced telomerase activity. This C-terminal fragment interacted with human TERT (hTERT) in vivo and in vitro. Notably, stable expression of PinX1 or C-terminal 74 residues in HT1080 cells reduced tumor formation after injection into nude mice. Consistent with these findings, PinX1 depletion by antisense strategy in HT1080 cells produced tumors at a higher frequency after injection into nude mice (Zhou et al., 2001). In this regard, future development of PinX1-deficient mice may help manifest the importance of this molecule as a novel tumor suppressor and a regulator of telomerase and telomere in vivo.

\section{DNA Damage Response and Telomerase}

Telomere and its maintenance are essential for maintenance of genomic stability, which is well illustrated by the fact that $\mathrm{mTERC}^{-{ }^{-}}$mice exhibited impaired DNA repair and enhanced sensitivity to ionizing radiation (Wong et al., 2000). The interplay among various genes involved in DNA damage response repair pathways, and telomerse dysfunction has been investigated in different mouse models.

\section{ATM-deficient mouse}

ATM, the gene responsible for ataxia telangiectasia (A-T) is a kinase and crucial controller of cellular signaling, orchestrating the responses to DNA double strand breaks (Pandita, 2002). ATM is a mammalian homolog of yeast genes, TEL1, MEC1 and rad3, whose mutations cause defective telomere maintenance (Pandita, 2002). Importantly, A-T cells display higher frequency of chromosome end-to-end fusions and loss of telomeres (Pandita and Dhar, 2000; Pandita, 2002). ATM phosphorylates a number of nuclear proteins, including c-Abl tyrosine kinase, p53, BRCA1, NBS1 and PIN2/TRF1. These target genes are now found to be required for proper maintenance of mammalian telomeres (Pandita, 2002). Notably, telomere shortening in A-T cells is partially rescued by ectopic expression of hTERT (Wood et al., 2001). Human cell culture-based studies have revealed that compromised telomere structures and function, induced by expression of a trans-dominant negative 
form of TRF2, elicited ATM- and p53-dependent DNA damage checkpoint responses (Karlseder et al., 1999). Several Atm mutant mouse strains have been generated. These mice were viable and displayed most of the pleiotrophic features of the A-T phenotype, including genomic instability, progressive neurological degeneration, premature aging, and increased neoplasia incidence (Barlow et al., 1996; Elson et al., 1996; Xu et al., 1996; Herzog et al., 1998). Indeed, Atm deficiency influenced telomere shortening and telomere chromatin structure, especially meiotic telomere distribution (Barlow et al., 1996; Elson et al., 1996; Xu et al., 1996; Herzog et al., 1998; Scherthan et al., 2000).

\section{DNA-PK-deficient mouse}

DNA protein kinase (DNA-PK) complex is composed of DNA-PK catalytic subunit (DNA-PKcs) and Ku70:80 heterodimer and is critical for DNA repair by nonhomologous end-joining (NHEJ) (Durocher and Jackson, 2001). It was reported that mice homozygous for the severe combined immunodeficiency (scid) mutation have defective DNA-PK catalytic subunit (DNA-PKcs), and the telomeres in a murine scid cell lines are significantly longer than those in the corresponding wildtype cell line (Slijepcevic et al., 1997). This data was further confirmed by TRF analysis and quantitative fluorescence in situ hybridization (Q-FISH) using scid mice of various genetic backgrounds. In line with in vitro data, scid mice displayed significantly longer telomeres than wild-type mice. However, it should be noted that scid mutants might contain other genomic alterations. This notion is supported by the observation that DNA-PKcs-deficient mice generated by gene targeting do not show significant alterations in telomere length (Gilley et al., 2001; Goytisolo et al., 2001), but have a high level of telomere fusions, suggesting DNA-PKcs is critical for telomere capping. Recently, it was shown that DNA-PK complex is physically associated with mammalian telomeric DNA in vivo by chromatin immunoprecipitation assay, and these associations are not significantly influenced by DNA-damaging agents (d'Adda di Fagagna et al., 2001). Furthermore, Q-FISH results revealed that mouse embryonic fibroblasts (MEF) or ES cells derived from Ku70-or Ku80-deficient mice have shorter telomeres compared with those of wild-type mice (d'Adda di Fagagna et al., 2001). However, cells from mice deficient for XRCC4/DNA Ligase IV complex, another component of NHEJ, did not show significant telomere loss either by TRF analysis and Q-FISH (d'Adda di Fagagna et al., 2001). These data imply that $\mathrm{Ku}$ and possibly DNA-PKcs possess additional specialized roles at telomeres.

\section{Mouse deficient for both Ku86 and mTERC}

Espejel et al. (2002a) impaired both telomerase-mediated telomere maintenance and Ku86 function by generating double knockout (TERC ${ }^{-1} \mathrm{Ku}^{-{ }^{-1}}{ }^{-}$) mice. Previously, they observed reproducible telomere elongations in Ku86-deficient cells compared with wildtype controls (Samper et al., 2000). However, they found that Ku86 deficiency does not result in elongated telomeres in telomerase-deficient MEFs or bone marrow cells by Q-FISH. Interestingly, they found that telomeres of MEFs from different generation of TERC ${ }^{-1}$ $\mathrm{Ku} 86^{+/+}$and $\mathrm{TERC}^{-1-} \mathrm{Ku} 86^{-1-}$ did not display significant changes in length. It is plausible that Ku86 negatively regulates telomerase-dependent telomere elongation. End-to-end fusions of chromosome were frequent in both Ku86 and late generations of $\mathrm{mTERC}^{-1-}$ mice (Blasco et al., 1997; Samper et al., 2000). These fusions through p-arms (Robertsonian-like) were classified into two groups: those with detectable TTAGGG and those without detectable TTAGGG. Late generations of $\mathrm{mTERC}^{-/-}$mice showed end-to-end fusions lacking detectable TTAGGG, whereas $\mathrm{Ku}^{-\sigma^{-1}}$ mice exhibited fusions with detectable TTAGGG. Importantly, MEFs from increasing generation of $\mathrm{TERC}^{-1} \mathrm{Ku}^{-1-}$ mice exhibited decrease in the frequency of end-toend fusions without detectable TTAGGG compared with MEFs from mice deficient in mTerc alone. These data clearly demonstrated that Ku86 mediates the fusion of chromosomes with critically short telomeres, showing that these fusion events are mediated by NHEJ machinery (Espejel et al., 2002a). In addition, Ku86 deficiency rescued early germ cell apoptosis in the late-generation mTERC $^{-1-}$ mice (Lee et al., 1998; Espejel et al., 2002a), indicating a direct or indirect role of Ku86 in apoptosis of these cells elicited by critically short telomeres.

\section{Mouse deficient for both DNA-PK and mTerc}

The role of DNA-PKcs in telomere length maintenance has been reported in scid mutant mice or DNAPKcs deficient mice as mentioned above (Slijepcevic et al., 1997; d'Adda di Fagagna et al., 2001; Gilley et al., 2001; Goytisolo et al., 2001). However these studies did not fully demonstrate the role of DNA$\mathrm{PKcs}$ in telomerase-based telomere maintenance. To this end, Espejel et al. (2002b) generated mice that are deficient for both mTERC and DNA-PKcs. Unexpectedly, doubly deficient mice showed reduced fertility even in the first generation (G1), and were infertile in the second generation. G1 $\mathrm{mTERC}^{-/}$DNA$\mathrm{PKCs}^{-1-}$ mice showed a severe reduction in testis size and striking depletion in germ cells, which are the most characteristic phenotypes of $\mathrm{mTERC}^{-/}$mice in a late-generation (Lee et al., 1998). One explanation for this observation is that $\mathrm{G} 1$ doubly deficient mice 
may have faster shortening of the telomeres, compared with $\mathrm{mTERC}^{-t-}$ or DNA-PKCs ${ }^{-t}$ mice. Of note, the severity of the telomere shortening of G1 DNA$\mathrm{PKCs}^{-1-} \mathrm{mTERC}^{-/}$testis was equivalent to that of the late generations of $\mathrm{mTERC}^{-1}$. This faster rate of telomere loss was also evident in different cell types, including MEFs and splenocytes. Therefore, DNAPKcs activity, but not Ku86, functionally interacts with telomerase in maintaining telomere length. Concomitant with a faster rate of telomere loss, MTERC ${ }^{-1}$ DNA$\mathrm{PKCs}^{-1-}$ mice also showed an earlier loss of viability than the corresponding telomerase-deficient controls. However, this loss of viability was not mediated by a further increase in end-to-end fusions or apoptosis. Importantly, they found that even short telomeres in the absence of DNA-PKcs activity do not lead to increased end-to-end fusions. Furthermore, apoptosis triggered by telomere shortening also was not increased in mTERC $^{-/}$DNA-PKcs ${ }^{-/}$mice. In conclusion, DNA-PKcs is required for apoptosis signaling by telomere dysfunction and essential for the fusion of short telomeres.

\section{PARP1-deficient mouse}

Poly (ADP-ribose) polymerase (PARP) senses DNAstrand breaks and is involved in the maintenance of genomic stability (Tong et al., 2001) Several groups have produced PARP-1 knockout mice and two of them reported on the role of PARP-1 on telomere maintenance (Wang et al., 1995; De Murcial et al., 1997). PARP1-deficient mice developed by Wang et al were found to have dramatically shorter telomeres and an increased frequency of end-to-end fusions (d'Adda di Fagagna et al., 1999). However, PARP1 knockout mice from De Murcial et al. displayed normal telomere length and a slight increase in endto-end fusions (Robertsonians and dicentrics) compared with wild-types (Samper et al., 2001). Such discrepancy could be attributed to the difference in genetic background of these PARP1-deficient mice. Importantly, PARP1-deficiency in the $\mathrm{p} 53^{-f_{-}}$genetic background results in heterogeneity of telomere length, including very long and very short telomere or even uncapped chromosomes compared with those from wild-type, PARP1-deficient or p53-deficient cells (Tong et al., 2001). Together with a recent finding that PARP-1 interacts with telomerase (Cao et al., 2002), these observations raise the possibility of involvement of PARP-1 in the telomere length regulation.

\section{Telomerase: For or against cancer?}

The original hypothesis on telomere and telomerase in cancer was that repression of telomerase activity in human cells serves as a tumor suppressor mechanism and that re-activation of telomerase is neces- sary for immortal growth of tumor cells. In support of this hypothesis, early studies in $\mathrm{mTERC}^{-1}$ mice described suppression of tumor formation in Ink4a deficient mice (Greenberg et al., 1999). However, the following studies in mTERC-deficient mice revealed a more complex phenotype. Despite the inactivation of telomerase, the frequency of tumor development and genomic instability increased in mTERC-deficient mouse models due to increased telomere dysfunction (Blasco et al., 1997; Lee et al., 1998; Chin et al., 1999; Greenberg et al., 1999). Based on this observation, different investigators began to investigate the relationship between telomerase and tumor suppressors using mouse models.

\section{Mouse deficient for both p53 and mTERC}

Chin and colleagues observed that telomere shortening and subsequent chromosomal fusions in $\mathrm{mTERC}^{-1}$ mice resulted in activation of $\mathrm{p} 53$, leading to growth arrest and/or apoptosis in testis compared with wild-type controls (Chin et al., 1999). The authors explored the interactions between telomere dysfunction and p53 in cells and organs of telomerase-deficient mice by generating mice doubly null for MTERC and p53. Interestingly, reduced fertility of $\mathrm{G} 6 \mathrm{mTERC}^{-/}$ mice was rescued by $\mathrm{p} 53$ deficiency, enabling generation of $\mathrm{G} 7$ or $\mathrm{G} 8 \mathrm{mTERC}^{-1}$ mice under p53-deficient genetic background. In addition, tumorigenic initiation was enhanced in mTERC ${ }^{-1} \mathrm{p} 53^{-t_{-}}$MEFs shown by a transformation assay with Myc/Ras cooperation compared with $\mathrm{mTERC}^{-/} \mathrm{p} 53^{-/-}$MEFs cotransfected with mTERC expression vector. However, when these cells were injected into scid mice, they did not show any significant differences in tumor formation. Therefore, deletion of p53 significantly attenuated the adverse cellular and organismal effects of telomere dysfunction, but only during the earliest stages of genetic crisis. These findings studies indicate a key role for p53 in cellular response to genetic crisis elicited by telomere dysfunctions.

\section{Mouse deficient for both Ink4a and mTERC}

Greenberg et al. (1999) have produced successive generation of mice doubly deficient for mTERC and Ink4a tumor suppressor genes. Notably, Ink4a-deficient mice exhibit highly penetrant cancer phenotype, and Ink4a $a^{-1-}$ MEFs are readily transformed by cellular oncogenes, possess a high rate of colony formation, and lack a senescent arrest phase in culture (Serrano et al., 1996). Furthermore, tumors from Ink4a-deficient mice (primary solid and lymphoid tumors) showed higher telomerase activity, establishing Ink4a $a^{-/-}$mice as an ideal in vivo model for testing the importance of telomerase and telomere functions in the tumorigenic processes. Greenberg et al. (1999) employed two- 
step DMBA/UVB carcinogenesis protocol to assess the incidence, latency, clinical behavior, and histological grade of primary tumors in the successive generations of mice doubly null for mTERC and Ink4a. As expected, they observed a decrease in tumors and an increase in survival in G4 and G5 mTERC ${ }^{-1-} \operatorname{lnk} 4 \mathrm{a}^{-1-}$ mice, suggesting that significant telomere shortening and loss of telomere function in late-generation mTERC $^{-1}$ mice reduces cancer incidence in vivo in mice deficient for the Ink4a allele (Greenberg et al., 1999). In consistent with this finding, the late generation mTERC $^{-1-}$ Ink4a $a^{-/-}$MEFs showed impaired cellular growth, decreased colony formation, and increased resistance to oncogene-induced colony formation. Importantly, these defects were significantly rescued by reintroduction of mTERC alone (Greenberg et al., 1999).

\section{Mouse deficient for both ATM and mTERC}

The telomeric phenotype of ATM-deficient mice was further evaluated by crossing with mTERC-deficient mice to study the functional interaction of ATM and telomeres in vivo (Wong et al., 2003). Expectedly, these compound mutants showed increased telomere erosion and genomic instability. However, the incidence of T-cell lymphomas associated with the ATM deficiency was reduced in these compounds mice. A generalized proliferation defect was evident in all cell types and tissues examined, and this defect extended to tissue stem/progenitor cell compartments, thereby providing a basis for progressive multi-organ system compromise, accelerated aging and premature death in these compound mice. Thus, ATM deficiency and telomere dysfunction act together to impair cellular and whole-organism viability, supporting the view that aspects of A-T pathophysiology are linked to the functional state of telomeres and the impairment of stem/ progenitor cell reserves.

\section{Rb family genes and telomere}

The tumor suppressor pathway cdkn2a/Rb1 has long been implicated as a barrier to immortalization. Forced expression of Rb1 in squamous cell carcinomas lines results in decreased telomerase activity (Nguyen and Crowe, 1999). However, how Rb1 negatively regulates telomerase is largely unknown. There have been recent reports that $\mathrm{Rb} 1$ family genes, including Rb1 (Retinoblastoma 1), Rbl2 (Retinoblastoma-like 2), and Rbl2 (Retinoblastoma-like 2), have a connection to the telomere length regulation in MEFs. MEFs doubly deficient for Rbl1 and Rbl2 (DKO) or triply deficient for Rbl1, Rbl2 and Rb1 (TKO) possess elongated telomeres compared with those of wild type or Rb1 null cells (Garcia-Cao et al., 2002). Importantly, the telomerase activity in DKO or TKO MEFs did not show significant changes compared with wild-type
MEFs, suggesting that telomere elongation was not due to the increase in telomerase activity (Garcia-Cao et al., 2002). This rapid elongation of telomeres by inactivation of $\mathrm{Rb} 1$ family genes could be a possible mechanism for the extended life span of cells elicited by a number of viral oncoproteins such as Simian virus 40 large $T$ antigen, human papilloma virus $E 7$ and adenovirus E1A which interact with $\mathrm{Rb}$ (Lee and Cho, 2002). However, further studies are needed to unravel how $\mathrm{Rb} 1$ family genes are involved in telomere length regulation.

\section{K5-mTERT transgenic mice}

González-Suárez and coworkers generated K5-mTERT transgenic mice in which TERT expression was targeted to basal keratinocytes and various stratified epithelia using bovine keratin 5 (K5) promoter and examined the impact of TERT overexpression on tumorigenesis (González-Suárez et al., 2001). Although stratified epithelia of these transgenic mice were histologically normal, they showed increased susceptibility to tumor development upon administration of chemical carcinogens. Moreover, K5-TERT mice showed increased sensitivity to the mitogenic effects of phorbol esters and accelerated wound healing in skin. In the following study, they demonstrated that K5TERT mice had a decreased life span compared to wild-type mice, which was associated with a higher incidence of preneoplastic and neoplastic lesions in various tissue types with increasing age (GonzálezSuárez et al., 2002). The increased tumor incidence in K5-TERT mice was seen only at old ages. Increased cancer incidence and the reduced viability of K5-TERT mice were aggravated in a $\mathrm{p}^{+1 /-}$ genetic background suggesting that TERT cooperates with loss of p53 function in inducing tumorigenesis. Interestingly, the changes observed in these two studies, including the increased spontaneous cancer incidence of K5-TERT mice, were not dependent upon the net telomere length.

\section{pCAGGS-mTERT transgenic mice}

Artandi et al. generated lines of transgenic mice that constitutively expressed mTERT in a variety of tissues under the control of $\beta$-actin promoter and CMV enhancer elements (Artandi et al., 2002). In contrast to the findings of K5-TERT transgenic mice, these mTERT transgenic mice did not show increased sensitivity to the mutagen, DMBA and failed to mount a differential response in the rate of spontaneous tumor formation in intercross with Ink4a-deficient mice, despite the increased TERT expression and telomerase enzymatic activity in various tissues. However, a significant finding was that TERT overexpression promoted development of mammary carcinoma in aging 
Table 2. Novel functions of telomerase.

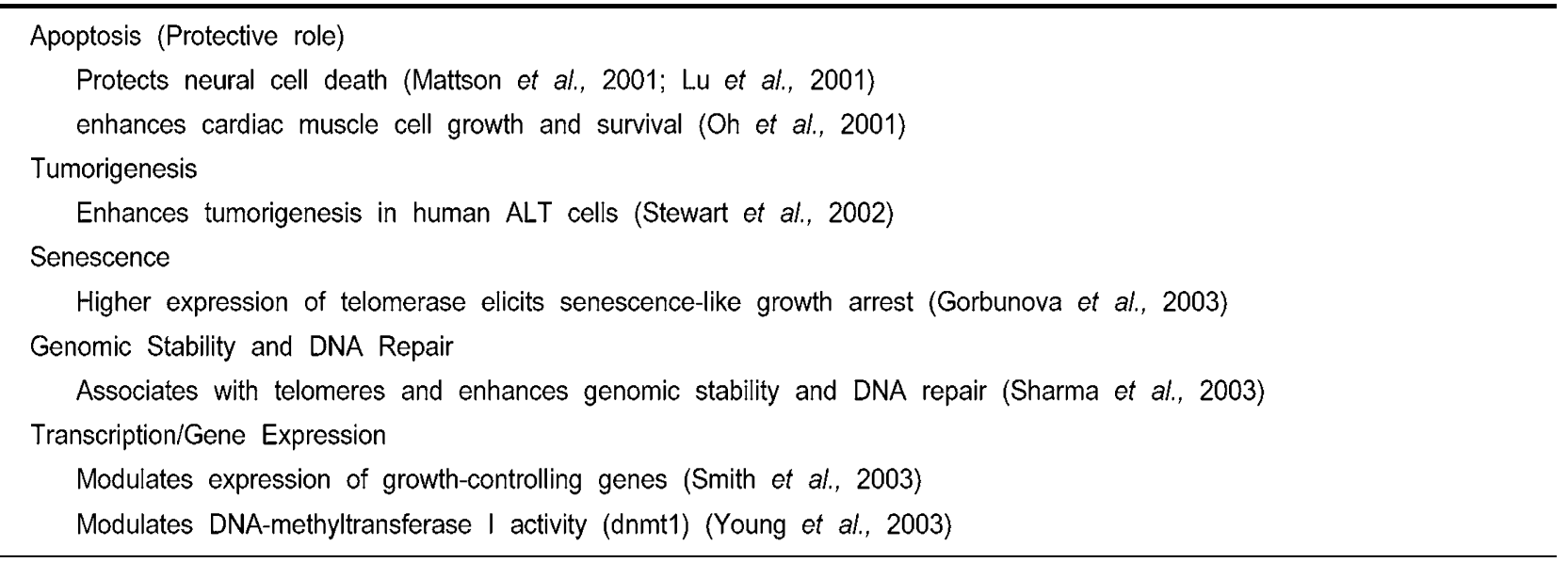

mice. The authors pointed out that the increased incidence of mammary carcinoma in aging mTERT transgenic mice was evident even in the setting of abundant telomere reserve, which suggests that the mammary tumor-promoting action of telomerase was not dependent on the telomere length. Taken together, studies on K5-mTERT and pCAGGS-mTERT transgenic mice suggest that telomerase is able to promote cell survival and proliferation and contribute to tumorigenesis. It is of interest that changes observed in transgenic models of mouse TERT overexpression were present in the absence of a discernable alternation in the net telomere length, which suggests that telomerase, in addition to its role in telomere maintenance, serve novel roles in maintaining tissue homeostasis.

\section{Future Perspective}

\section{Telomerase in a new dimension}

Previous studies on telomerase have been limited to its catalytic activity and its role in telomere maintenance and dysfunction. However, recently telomerase has been shown to increase tumorigenic potential in vivo in the absence of an increase in telomere length (Artandi et al., 2002; González-Suárez et al., 2002; Stewart et al., 2002), and evidences for novel functions of telomerase have been accumulating. In support of this notion, Oh et al. observed that the expression of human TERT in mouse myocardium delayed the cell cycle exit by ventricular myocytes and led to late-onset cardiac hypertrophy (Oh et al., 2001). Moreover, TERT expression conferred protection against cardiac myocyte injury after ischemic injury in vivo. A more recent study by the same group demonstrated that TERT overexpression in adult mouse myocardium also provide protection from apo- ptosis, fibrosis, and systolic dysfunction after mechanical stress (Oh et al., 2003). Additionally, there are a number of reports indicating that TERT plays a cytoprotective role against damaging agents and conditions (Summarized in Table 2). In this regard, our group made a recent observation that transgenic mice that overexpress mTERT were significantly resistant to ischemic brain injury. Among different routes of ischemic neuronal death, including excitotoxicity, oxidative stress, and apoptosis, NMDA receptor-mediated excitotoxicity was attenuated in primary cortical cell cultures from TERT over-expressing mice (Kang et al., manuscript submitted). These findings support the notion that telomerase might have novel and telomere-indepenent functions.

Although numerous studies on telomerase have examined the effects of telomerase over-expression in vitro, few studies have been conducted at the organismal level. In addition to currently available TERTover-expressing transgenic mice, mTERT-deficient mice have been regenerated by at least two groups (Yuan et al., 1999; Liu et al., 2000a). These mTERTdeficient mice in combination with mTERC-deficient mice should serve as a valuable tool in testing various hypotheses on novel functions of telomerase. For instance, the dependency of newly proposed roles of telomerase on its catalytic activity can be deciphered using these mouse models. Furthermore, combining these tools with TERT over-expressing mice will serve as another useful and effective tool in studying the novel functions of the telomerase during various stress conditions in vivo and in understanding the molecular mechanisms behind them.

\section{Acknowledgment}

This work was supported by $21 \mathrm{C}$ Frontier Functional Human Genome Project from MOST, NRL (M1- 
0203-00-0108), and KOSEF (SRC-MTRC).

\section{References}

Artandi SE, Alson S, Tietze MK, Sharpless NE, Ye S, Greenberg RA, Castrillon DH, Horner JW, Weiler SR, Carrasco $\mathrm{RD}$, DePinho RA. Constitutive telomerase expression promotes mammary carcinomas in aging mice. Proc Natl Acad Sci USA 2002;99:8191-6

Bachand F, Boisvert FM, Cote J, Richard S, Autexier C. The product of the survival of motor neuron (SMN) gene is a human telomerase-associated protein. Mol Biol Cell 2002; 13:3192-202

Barlow C, Hirotsune S, Paylor R, Liyanage M, Eckhaus $M$, Collins $F$, Shiloh $Y$, Crawley JN, Ried T, Tagle $D$, Wynshaw-Boris A. Atm-deficient mice: a paradigm of ataxia-telangiectasia. Cell 1996;86:159-71

Baumann P, Podell E, Cech TR. Pot1, the putative telomere end-binding protein in fission yeast and humans. Science 2001;292:1171-5

Baumann P, Podell E, Cech TR. Human Pot1 (protection of telomeres) protein: cytolocalization, gene structure, and alternative splicing. Mol Cell Biol 2002;22:8079-87

Blackburn EH. Structure and function of telomeres. Nature 1991;350:569-73

Blasco MA, Funk W, Villeponteau B, Greider CW. Functional characterization and developmental regulation of mouse telomerase RNA. Science 1995;269:1267-70

Blasco MA, Lee HW, Hande MP, Samper E, Lansdorp PM, DePinho RA, Greider CW. Telomere shortening and tumor formation by mouse cells lacking telomerase RNA. Cell 1997;91:25-34

Broccoli D, Smogorzewska A, Chong L, de Lange T. Human telomeres contain two distinct Myb-related proteins, TRF1 and TRF2. Nat Genet 1997;17:231-5

Cao Y, Li H, Deb S, Liu JP. TERT regulates cell survival independent of telomerase enzymatic activity. Oncogene $2002 \cdot 21: 3130-8$

Chin L, Artandi SE, Shen Q, Tam A, Lee SL, Gottlieb GJ, Greider CW, DePinho RA. p53 deficiency rescues the adverse effects of telomere loss and cooperates with telomere dysfunction to accelerate carcinogenesis. Cell 1999;97:527-38

d'Adda di Fagagna F, Hande MP, Tong WM, Lansdorp PM, Wang ZQ, Jackson SP. Functions of poly (ADPribose) polymerase in controlling telomere length and chromosomal stability. Nat Genet 1999;23:76-80

d'Adda di Fagagna F, Hande MP, Tong WM, Roth D, Lansdorp PM, Wang ZQ, Jackson SP. Effects of DNA nonhomologous end-joining factors on telomere length and chromosomal stability in mammalian cells. Curr Biol 2001; $11: 1192-6$

de Murcia JM, Niedergang $C$, Trucco $C$, Ricoul M, Dutrillaux B, Mark $M$, Oliver FJ, Masson M, Dierich $A$, LeMeur $M$, Walztinger $C$, Chambon $P$, de Murcia $G$.
Requirement of poly(ADP-ribose) polymerase in recovery from DNA damage in mice and in cells. Proc Natl Acad Sci USA 1997:94:7303-7

Dokal I. Dyskeratosis congenita in all its forms. $\mathrm{Br} \mathrm{J}$ Haematol 2000:110:768-79

Dragon $F$, Pogacic $V$, Filipowicz $W$. In vitro assembly of human H/ACA small nucleolar RNPs reveals unique features of U17 and telomerase RNAs. Mol Cell Biol 2000; 20:3037-48

Durocher D, Jackson SP. DNA-PK, ATM and ATR as sensors of DNA damage: variations on a theme? Curr Opin Cell Biol 2001;13:225-31

Elson A, Wang Y, Daugherty CJ, Morton CC, Zhou F, Campos-Torres J, Leder P. Pleiotropic defects in ataxiatelangiectasia protein-deficient mice. Proc Natl Acad Sci USA 1996:93:13084-9

Espejel S, Franco S, Rodriguez-Perales S, Bouffler SD, Cigudosa JC, Blasco MA. Mammalian Ku86 mediates chromosomal fusions and apoptosis caused by critically short telomeres. EMBO J 2002a;21:2207-19

Espejel S, Franco S, Sgura A, Gae D, Bailey SM, Taccioli GE, Blasco MA. Functional interaction between DNA-PKcs and telomerase in telomere length maintenance. EMBO J $2002 b ; 21: 6275-87$

Ford LP, Suh JM, Wright WE, Shay JW. Heterogeneous nuclear ribonucleoproteins $\mathrm{C} 1$ and $\mathrm{C} 2$ associate with the RNA component of human telomerase. Mol Cell Biol. 2000; 20:9084-91

Ford LP, Shay JW, Wright WE. The La antigen associates with the human telomerase ribonucleoprotein and influences telomere length in vivo. RNA 2001;7:1068-75

Garcia-Cao M, Gonzalo S, Dean D, Blasco MA. A role for the $\mathrm{Rb}$ family of proteins in controlling telomere length. Nat Genet 2002;32:415-9

Gilley D, Tanaka H, Hande MP, Kurimasa A, Li GC, Oshimura M, Chen DJ. DNA-PKcs is critical for telomere capping. Proc Natl Acad Sci USA 2001;98:15084-8

Gonzalez-Suarez E, Samper E, Ramirez A, Flores JM, Martin-Caballero J, Jorcano JL, Blasco MA. Increased epidermal tumors and increased skin wound healing in transgenic mice overexpressing the catalytic subunit of telomerase, mTERT, in basal keratinocytes. EMBO J 2001; 20:2619-30

Gonzalez-Suarez E, Flores JM, Blasco MA. Cooperation between p53 mutation and telomerase transgenic expression in spontaneous cancer development. Mol Cell Biol 2002;22:7291-301

Gorbunova V, Seluanov A, Pereira-Smith OM. Evidence that high telomerase activity may induce a senescent-like growth arrest in human fibroblasts. J Biol Chem 2003; 278:7692-8.

Gottlieb TM, Jackson SP. The DNA-dependent protein kinase: requirement for DNA ends and association with $\mathrm{Ku}$ antigen. Cell 1993;72:131-42

Goytisolo FA, Samper E, Edmonson S, Taccioli GE, Blasco MA. The absence of the DNA-dependent protein kinase 
catalytic subunit in mice results in anaphase bridges and in increased telomeric fusions with normal telomere length and G-strand overhang. Mol Cell Biol 2001;21:3642-51

Greenberg RA, O'Hagan RC, Deng H, Xiao Q, Hann SR, Adams RR, Lichtsteiner S, Chin L, Morin GB, DePinho RA. Short dysfunctional telomeres impair tumorigenesis in the INK4a (delta2/3) cancer-prone mouse. Cell 1999;97:51525

Greider CW. Telomeres. Curr Opin Cell Biol 1991;3:444-51

Griffith JD, Comeau L, Rosenfield S, Stansel RM, Bianchi A, Moss $\mathrm{H}$, de Lange T. Mammalian telomeres end in a large duplex loop. Cell 1999;97:503-14

Harley CB, Villeponteau B. Telomeres and telomerase in aging and cancer. Curr Opin Genet Dev 1995;5:249-55.

Harrington L, McPhail T, Mar V, Zhou W, Oulton R, Bass $\mathrm{MB}$, Arruda I, Robinson MO. A mammalian telomeraseassociated protein. Science 1997;275:973-7

Hathcock KS, Hemann MT, Opperman KK, Strong MA, Greider CW, Hodes RJ. Haploinsufficiency of mTR results in defects in telomere elongation. Proc Natl Acad Sci USA 2002;99:3591-6

Hayflick L, Moorhead PS. The serial cultivation of human diploid cell strains. Exp Cell Res 1961;25:585-621

Heiss NS, Knight SW, Vulliamy TJ, Klauck SM, Wiemann S, Mason PJ, Poustka A, Dokal I. X-linked dyskeratosis congenita is caused by mutations in a highly conserved gene with putative nucleolar functions. Nature Genet 1998; 19:32-8

Hemann MT, Strong MA, Hao LY, Greider CW. The shortest telomere, not average telomere length, is critical for cell viability and chromosome stability. Cell 2001; 107:67-77

Herrera E, Samper E, Blasco MA. Telomere shortening in mTR-/ embryos is associated with failure to close the neural tube. EMBO J 1999;18:1172-81

Herzog KH, Chong M, Kapsetaki M, Morgan JI, McKinnon PJ. Requirement of Atm in ionizing radiation-induced cell death in the developing central nervous system. Science 1998;280:1089-91

Holt SE, Aisner DL, Baur J, Tesmer VM, Dy M, Ouellette M, Trager JB, Morin GB, Toft DO, Shay JW, Wright WE, White MA. Functional requirement of p23 and Hsp90 in telomerase complexes. Genes Dev 1999;13:817-26

Kaminker PG, Kim SH, Taylor RD, Zebarjadian Y, Funk WD, Morin GB, Yaswen P, Campisi J. TANK2, a new TRF1-associated poly (ADP-ribose) polymerase, causes rapid induction of cell death upon overexpression. J Biol Chem 2001;276:35891-9

Kang SS, Kwon T, Kwon DY, Do SI. Akt protein kinase enhances human telomerase activity through phosphorylation of telomerase reverse transcriptase subunit. J Biol Chem 1999;274:13085-90

Karlseder J, Broccoli D, Dai Y, Hardy S, de Lange T. p53and ATM-dependent apoptosis induced by telomeres lacking TRF2. Science 1999;283:1321-5
Kharbanda S, Kumar V, Dhar S, Pandey $P$, Chen $C$, Majumder $P$, Yuan ZM, Whang $Y$, Strauss W, Pandita TK, Weaver D, Kufe D. Regulation of the hTERT telomerase catalytic subunit by the c-Abl tyrosine kinase. Curr Biol 2000;10:568-75

Kickhoefer VA, Liu Y, Kong LB, Snow BE, Stewart PL, Harrington L, Rome LH. The Telomerase/vault-associated protein TEP1 is required for vault RNA stability and its association with the vault particle. J Cell Biol 2001;152: 157-64

Kim NW, Piatyszek MA, Prowse KR, Harley CB, West MD, Ho PL, Coviello GM, Wright WE, Weinrich SL, Shay JW. Specific association of human telomerase activity with immortal cells and cancer. Science 1994;266:2011-5

Kim SH, Kaminker P, Campisi J. TIN2, a new regulator of telomere length in human cells. Nat Genet 1999;23: 405-12

Kishi S, Zhou XZ, Ziv $Y$, Khoo C, Hill DE, Shiloh $Y$, Lu KP. Telomeric protein Pin2/TRF1 as an important ATM target in response to double strand DNA breaks. J Biol Chem 2001;276:29282-91

Knight SW, Vulliamy TJ, Morgan B, Devriendt K, Mason PJ, Dokal I. Identification of novel DKC1 mutations in patients with dyskeratosis congenita: implications for pathophysiology and diagnosis. Hum Genet 2001;108: 299-303

Le S, Sternglanz R, Greider CW. Identification of two RNA-binding proteins associated with human telomerase RNA. Mol Biol Cell 2000;11:999-1010

Lee $C$, Cho $Y$. Interactions of SV40 large $T$ antigen and other viral proteins with retinoblastoma tumour suppressor. Rev Med Virol 2002;12:81-92

Lee HW, Blasco MA, Gottlieb GJ, Horner JW 2nd, Greider $\mathrm{CW}$, DePinho RA. Essential role of mouse telomerase in highly proliferative organs. Nature 1998;392:569-74

Li B, Oestreich S, de Lange T. Identification of human Rap1: implications for telomere evolution. Cell 2000;101: 471-83

Liu Y, Snow BE, Hande MP, Yeung D, Erdmann NJ, Wakeham A, Itie A, Siderovski DP, Lansdorp PM, Robinson $\mathrm{MO}$, Harrington $\mathrm{L}$. The telomerase reverse transcriptase is limiting and necessary for telomerase function in vivo. Curr Biol 2000a;10:1459-62

Liu Y, Snow BE, Hande MP, Baerlocher G, Kickhoefer VA, Yeung D, Wakeham A, Itie A, Siderovski DP, Lansdorp PM, Robinson MO, Harrington L Telomerase-associated protein TEP1 is not essential for telomerase activity or telomere length maintenance in vivo. Mol Cell Biol 2000b; 20:8178-84

Lu C, Fu W, Mattson MP. Telomerase protects developing neurons against DNA damage-induced cell death. Brain Res Dev Brain Res 2001;131:167-71

Mattson MP, Fu W, Zhang P. Emerging roles for telomerase in regulating cell differentiation and survival: a neuroscientist's perspective. Mech Ageing Dev 2001;122: $659-71$

Meyerson M, Counter CM, Eaton EN, Ellisen LW, Steiner $P$, Caddle SD, Ziaugra L, Beijersbergen RL, Davidoff MJ, 
Liu Q, Bacchetti S, Haber DA, Weinberg RA. hEST2, the putative human telomerase catalytic subunit gene, is up-regulated in tumor cells and during immortalization. Cell 1997;90:785-95

Mitchell JR, Wood E, Collins $\mathrm{K}$ A telomerase component is defective in the human disease dyskeratosis congenita. Nature 1999;402:551-5

Nakayama J, Saito $M$, Nakamura $H$, Matsuura A, Ishikawa F. TLP1: a gene encoding a protein component of mammalian telomerase is a novel member of WD repeats family. Cell 1997;88:875-84

Nguyen DC, Crowe DL. Intact functional domains of the retinoblastoma gene product $(\mathrm{pRb})$ are required for downregulation of telomerase activity. Biochem Biophys Acta 1999;1445:207-15

Niida $H$, Matsumoto $T$, Satoh $H$, Shiwa $M$, Tokutake $Y$, Furuichi $Y$, Shinkai $Y$. Severe growth defect in mouse cells lacking the telomerase RNA component. Nat Genet 1998; 19:203-6

Oh H, Taffet GE, Youker KA, Entman ML, Overbeek PA, Michael LH, Schneider MD. Telomerase reverse transcriptase promotes cardiac muscle cell proliferation, hypertrophy, and survival. Proc Natl Acad Sci USA 2001; 98:10308-13

Oh H, Wang SC, Prahash A, Sano M, Moravec CS, Taffet GE, Michael LH, Youker KA, Entman ML, Schneider MD. Telomere attrition and Chk2 activation in human heart failure. Proc Natl Acad Sci USA 2003;100:5378-83

Pandita TK, Dhar S. Influence of ATM function on interactions between telomeres and nuclear matrix. Radiat Res 2000;154:133-9

Pandita TK. ATM function and telomere stability. Oncogene 2002;21:611-8

Pogacic V, Dragon F, Filipowicz W. Human H/ACA small nucleolar RNPs and telomerase share evolutionarily conserved proteins NHP2 and NOP10. Mol Cell Biol 2000; 20:9028-40

Rudolph KL, Chang S, Lee HW, Blasco M, Gottlieb GJ, Greider C, DePinho RA. Longevity, stress response, and cancer in aging telomerase-deficient mice. Cell 1999; 96: $701-12$

Rudolph KL, Chang S, Millard M, Schreiber-Agus N, DePinho RA. Inhibition of experimental liver cirrhosis in mice by telomerase gene delivery. Science 2000;287: 1253-8

Ruggero D, Grisendi S, Piazza F, Rego E, Mari F, Rao $\mathrm{PH}$, Cordon-Cardo C, Pandolfi PP. Dyskeratosis congenita and cancer in mice deficient in ribosomal RNA modification. Science 2003;299:259-62

Samper E, Goytisolo FA, Slijepcevic P, van Buul PP, Blasco MA. Mammalian Ku86 protein prevents telomeric fusions independently of the length of TTAGGG repeats and the G-strand overhang. EMBO Rep 2000;1:244-52.

Samper E, Goytisolo FA, Menissier-de Murcia J, GonzalezSuarez E, Cigudosa JC, de Murcia G, Blasco MA. Normal telomere length and chromosomal end capping in poly (ADP-ribose) polymerase-deficient mice and primary cells despite increased chromosomal instability. J Cell Biol $2001 ; 154: 49-60$

Scherthan $H$, Jerratsch M, Dhar S, Wang YA, Goff SP, Pandita TK. Meiotic telomere distribution and Sertoli cell nuclear architecture are altered in Atm- and Atm-p53deficient mice. Mol Cell Biol 2000;20:7773-83

Serrano M, Lee $H$, Chin L, Cordon-Cardo C, Beach D, DePinho RA. Role of the INK4a locus in tumor suppression and cell mortality. Cell 1996;85:27-37

Sharma GG, Gupta A, Wang H, Scherthan H, Dhar S, Gandhi V, lliakis G, Shay JW, Young CS, Pandita TK. hTERT associates with human telomeres and enhances genomic stability and DNA repair. Oncogene 2003;22:13146

Shay JW, Wright WE, Werbin H. Defining the molecular mechanisms of human cell immortalization. Biochem Biophys Acta 1991;1072:1-7

Shay JW, Wright WE. Hayflick, his limit, and cellular ageing. Nat Rev Mol Cell Biol 2000;1:72-6

Shen M, Haggblom C, Vogt M, Hunter T, Lu KP. Characterization and cell cycle regulation of the related human telomeric proteins Pin2 and TRF1 suggest a role in mitosis. Proc Natl Acad Sci USA 1997;94:13618-23

Slijepcevic P, Hande MP, Bouffler SD, Lansdorp P, Bryant $\mathrm{PE}$. Telomere length, chromatin structure and chromosome fusigenic potential. Chromosoma 1997;106:413-21

Smith LL, Coller HA, Roberts JM. Telomerase modulates expression of growth-controlling genes and enhances cell proliferation. Nat Cell Biol 2003;5:474-9

Smith S, Giriat I, Schmitt A, de Lange T. Tankyrase, a poly (ADP-ribose) polymerase at human telomeres. Science 1998;282:1484-7

Stewart SA, Hahn WC, O'Connor BF, Banner EN, Lundberg AS, Modha $P$, Mizuno $H$, Brooks MW, Fleming $M$, Zimonjic DB, Popescu NC, Weinberg RA. Telomerase contributes to tumorigenesis by a telomere length-independent mechanism. Proc Natl Acad Sci USA 2002;99: 12606-11

Tong WM, Cortes U, Wang ZQ. Poly (ADP-ribose) polymerase: a guardian angel protecting the genome and suppressing tumorigenesis. Biochem Biophys Acta 2001;1552: 27-37

Tong WM, Hande MP, Lansdorp PM, Wang ZQ. DNA strand break-sensing molecule poly (ADP-Ribose) polymerase cooperates with p53 in telomere function, chromosome stability, and tumor suppression. Mol Cell Biol 2001;21:4046-54

Vulliamy TJ, Knight SW, Mason PJ, Dokal I. Very short telomeres in the peripheral blood of patients with X-linked and autosomal dyskeratosis congenita. Blood Cells Mol Dis 2001a;27:353-7

Vulliamy T, Marrone A, Goldman F, Dearlove A, Bessler $M$, Mason PJ, Dokal I. The RNA component of telomerase is mutated in autosomal dominant dyskeratosis congenita. Nature 2001b;413:432-5

Wang ZQ, Auer B, Stingl L, Berghammer $H$, Haidacher D, 
Schweiger $M$, Wagner EF. Mice lacking ADPRT and poly-ADP-ribosylation develop normally but are susceptible to skin disease. Genes Dev 1995;95:509-20

Wong KK, Chang S, Weiler SR, Ganesan S, Chaudhuri J, Zhu C, Artandi SE, Rudolph KL, Gottlieb GJ, Chin L, Alt FW, DePinho RA. Telomere dysfunction impairs DNA repair and enhances sensitivity to ionizing radiation. Nat Genet 2000;26:85-8

Wong KK, Maser RS, Bachoo RM, Menon J, Carrasco DR, Gu Y, Alt FW, DePinho RA. Telomere dysfunction and Atm deficiency compromises organ homeostasis and accelerates ageing. Nature 2003;421:643-8

Wood LD, Halvorsen TL, Dhar S, Baur JA, Pandita RK, Wright WE, Hande MP, Calaf G, Hei TK, Levine F, Shay JW, Wang JJ, Pandita TK. Characterization of ataxia telangiectasia fibroblasts with extended life-span through telomerase expression Oncogene 2001;20:278-88

Wright WE, Shay JW. Historical claims and current interpretations of replicative aging. Nat Biotechnol 2002;20: $682-8$
Xu Y, Ashley T, Brainerd EE, Bronson RT, Meyn SM, Baltimore D. Targeted disruption of ATM leads to growth retardation, chromosomal fragmentation during meiosis, immune defects and thymic lymphoma. Genes Dev 1996; $10: 2411-22$

Yeager TR, Neumann AA, Englezou A, Huschtscha LI, Noble JR, Reddel RR. Telomerase-negative immortalized human cells contain a novel type of promyelocytic leukemia (PML) body. Cancer Res 1999;59:4175-9

Young JI, Sedivy JM, Smith JR. Telomerase expression in normal human fibroblasts stabilizes DNA 5-methylcytosine transferase I (DNMT1). J Biol Chem 2003;278: 19904-8.

Yuan $X$, Ishibashi $S$, Hatakeyama $S$, Saito $M$, Nakayama $J$, Nikaido $R$, Haruyama $T$, Watanabe $Y$, Iwata $H$, lida $M$, Sugimura $H$, Yamada N, Ishikawa F. Presence of telomeric G-strand tails in the telomerase catalytic subunit TERT knockout mice. Genes Cells 1999;4:563-72

Zhou XZ, Lu KP. The Pin2/TRF1-interacting protein PinX1 is a potent telomerase inhibitor. Cell 2001;107:347-59 